Development of a Low Loss,

High Dielectric Strength

Microwave Substrate

D. Sanders, S. Sampayan, G. Caporaso, M. Rhodes, J. Watson, K. Slenes, J. Jacquina, R. De La Fuenta, L. Thurmond

June 14, 2006

2006 Power Modulator Conference Washington, DC, United States

May 13, 2006 through May 18, 2006 
This document was prepared as an account of work sponsored by an agency of the United States Government. Neither the United States Government nor the University of California nor any of their employees, makes any warranty, express or implied, or assumes any legal liability or responsibility for the accuracy, completeness, or usefulness of any information, apparatus, product, or process disclosed, or represents that its use would not infringe privately owned rights. Reference herein to any specific commercial product, process, or service by trade name, trademark, manufacturer, or otherwise, does not necessarily constitute or imply its endorsement, recommendation, or favoring by the United States Government or the University of California. The views and opinions of authors expressed herein do not necessarily state or reflect those of the United States Government or the University of California, and shall not be used for advertising or product endorsement purposes. 


\title{
Development of a Low Loss, High Dielectric Strength Microwave Substrate
}

\author{
D. Sanders, S. Sampayan, G. Caporaso, M. Rhodes, J. Watson \\ Lawrence Livermore National Laboratory, Livermore, CA 94551
}

K. Slenes, J. Jacquina, R. De La Fuenta, L. Thurmond

TPL, Inc, Albuquerque, NM 87109, USA

\begin{abstract}
This work describes a comparison of two candidate materials for pulse forming line fabrication with respect to bulk dielectric breakdown, frequency response of relative permittivity and dielectric loss. One material is a commercially available microwave substrate material that can be procured in sheet form without a high voltage specification while the other is a newly developed material that also comes in sheet form that can also be cast between the electrodes.
\end{abstract}

\section{INTRODUCTION}

The Dielectric Wall Accelerator described elsewhere [1] is an approach that permits a ten-fold improvement in the performance of particle accelerators. These systems require insulating materials between electrodes in configurations that permit the greatest possible electric field gradients. Here we report the dielectric loss and bulk breakdown strength results of a comparison of two candidate materials with a target relative permittivity $\left(\varepsilon_{\mathrm{r}}\right)$ of 10 .

\section{MATERIALS}

The first material considered in this study is a commercially available microwave substrate material (referred to as "composite 1"). This material is only available in sheet form with a variety of thicknesses and $\varepsilon_{\mathrm{r}}$ values.

The second material, referred to as "composite 2," was formulated from a mixture of nanoparticles of ferroelectric in a polymer matrix. The concentration of the mixture was chosen to provide the same $\varepsilon_{\mathrm{r}}$ of "composite 1." Composite 2 is available in the same sheet dimensions as "composite 1" and can also be cast between the electrodes to allow the improved voltage performance to be described below.

\section{DIELECTRIC LOSS}

One property of importance in our application is dielectric loss. Figure 1 shows a comparison of dielectric loss behavior as a function of frequency as measured with a spectrum analyzer for the two materials under consideration.

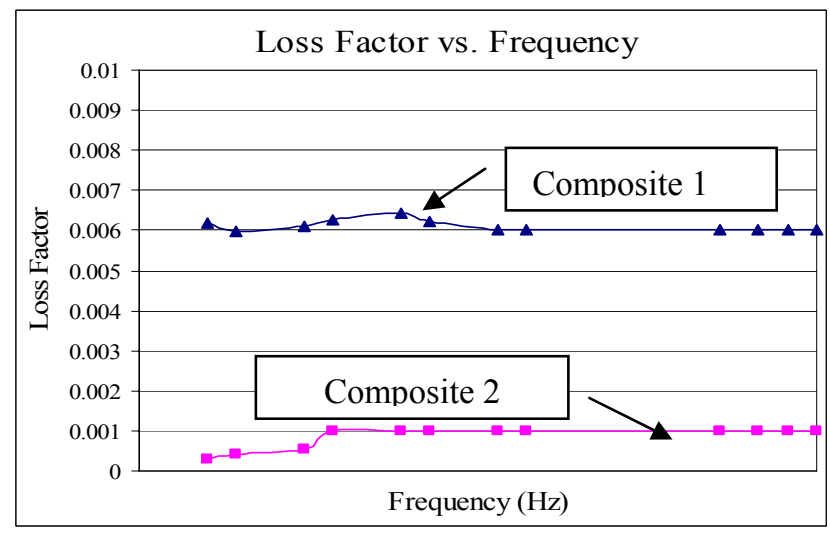

Fig.1. Comparison of dielectric loss behavior of the two materials.

The composite 2 material exhibits a 6 -fold reduction in dielectric loss.

\section{BULK BREAKDOWN}

The two types of bulk breakdown measurements carried in this study are illustrated in Fig. 2. In the sheet/oil version, sheets of material are mounted between the ball electrodes that were rotated after each test. Such ball rotation reduced the negative influence of arc pits formed after each breakdown event. Such pits are a known source of electric field enhancement that can lead to increased scatter in the data.

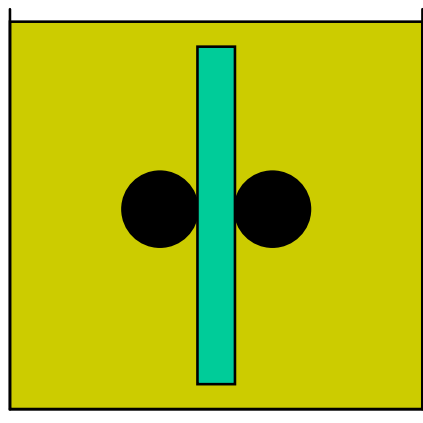

A

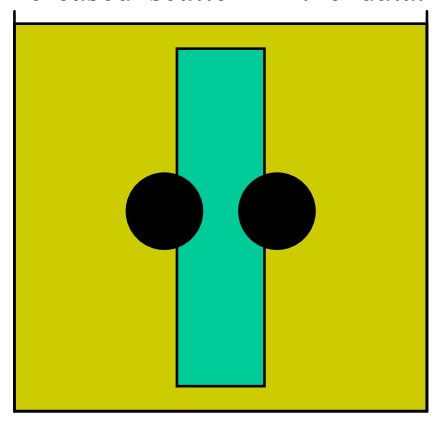

B
Fig 2. A.) "Sheet/oil" and B.) "Buried electrode" configurations of the bulk breakdown test. 


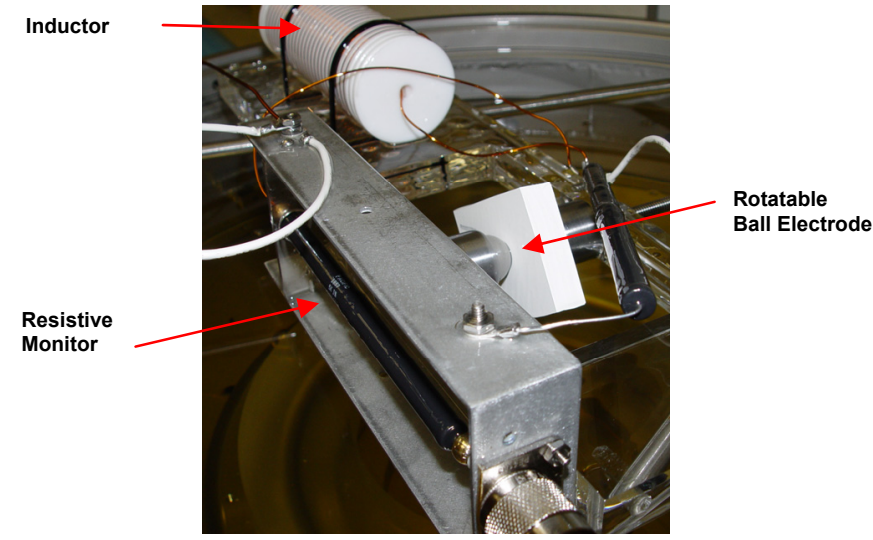

Fig. 3. Test station for pulsed bulk breakdown testing.

Fig. 3 shows a sample of the composite 2 in the test chamber in the sheet/oil arrangement. The ball electrodes were energized with a Marx generator (not shown) through a charge inductor to yield a pulse with a 50ns width FWHM as seen in Fig. 4.

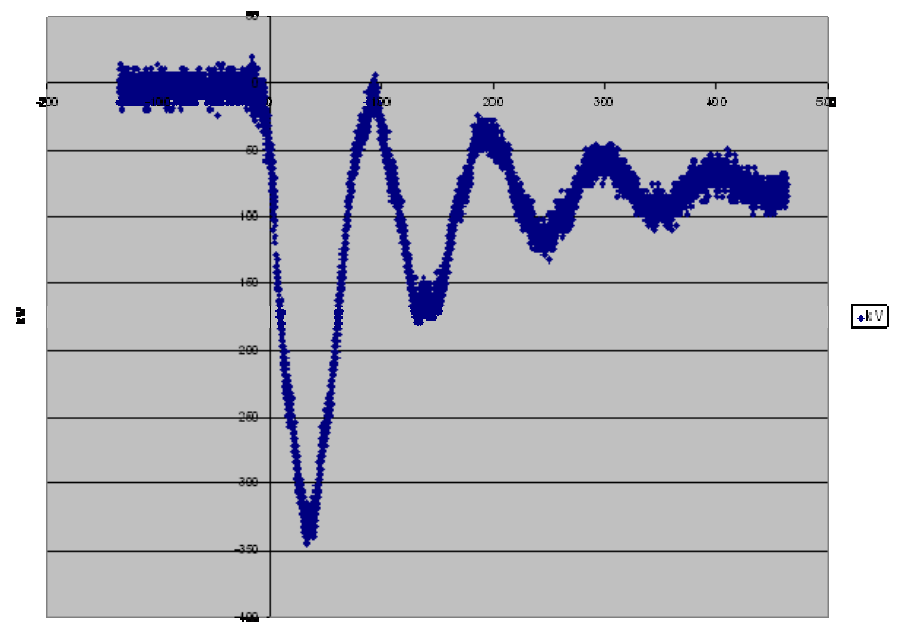

Time (ns)

Fig.4. Voltage trace recorded from the resistive monitor pictured in Fig. 2 calibrated to read in units of $\mathrm{kV}$.

Using either configuration the breakdown test consisted of subjecting the insulator to ever increasing pulsed voltages until the material failed or the voltage capability of the measuring system was exceeded $(\sim 315 \mathrm{kV})$. An oscilloscope trace was recorded on a computer after each voltage pulse to allow for subsequent analysis.

The results of these breakdown tests are summarized in Fig. 5 and Table I. Here the breakdown strength in all cases decreased with increasing distance between the electrodes. The composite 2 material in sheet form was approximately $30 \%$ stronger than the composite 1 material.

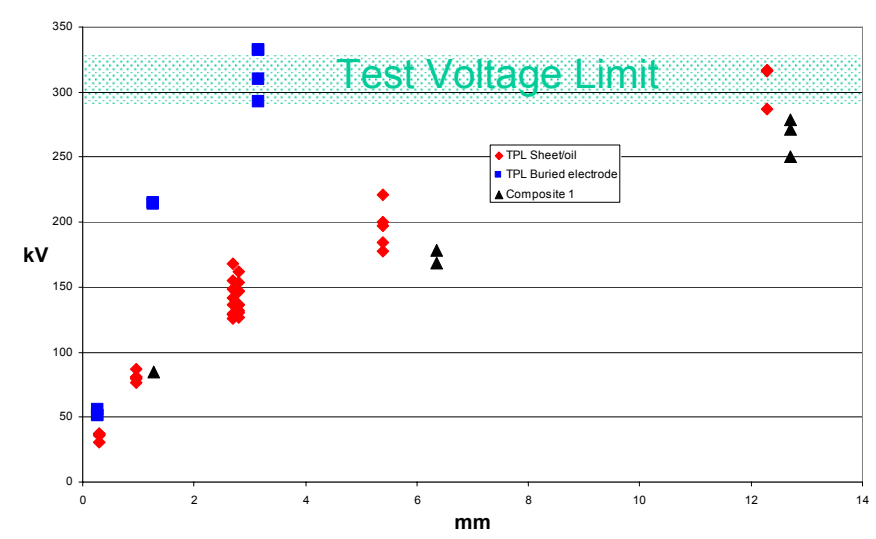

Fig. 5. Plot of voltage at breakdown vs. gap (mm).

TABLE I - Summary of bulk breakdown fields.

\begin{tabular}{|c|c|c|c|}
\hline & Composite 1 & \multicolumn{2}{|c|}{ Composite 2 } \\
\hline Gap (mm) & Sheet/oil & Sheet/oil & Buried Electrodes \\
\hline 1.27 & 669 & 840 & 1687 \\
\hline 3.17 & - & 518 & $>=1000^{*}$ \\
\hline 6.35 & 273 & 364 & $>496^{*}$ \\
\hline 12.7 & 210 & $>257^{*}$ & - \\
\hline
\end{tabular}

*Limited by voltage capability of test system.

The most significant improvement occurred in the case where the composite 2 material was used to bury the electrodes thereby shielding those electrodes from the lower relative permittivity $\left(\varepsilon_{\mathrm{r}} \approx 2.5\right)$ oil.

\section{DISCUSSION}

We believe the observed breakdown behavior can be attributed to three sources that will each be described. These are:

1. Geometric field enhancement,

2. Effect of different $\varepsilon_{\mathrm{r}}$ values in series,

3. The volume effect.

An equation that approximates geometric enhancement $\mathrm{f}$ is given by the expression [2]:

$$
\mathrm{f}=0.9(\mathrm{r}+\mathrm{d} / 2) / \mathrm{r}
$$

where, $\mathrm{r}=$ ball radius and $\mathrm{d}=$ gap

The effective field experienced by the dielectric is:

$$
\mathrm{E}_{\text {effective }}=(\mathrm{V} / \mathrm{d}) * \mathrm{f}
$$

For ball sizes used in this study and gaps less than $2 \mathrm{~mm}$ this geometric enhancement can be ignored. The enhancement factor is only 1.2 with a gap of $5 \mathrm{~mm}$, for instance.

The second, larger effect comes into play when there are two materials with significantly different $\varepsilon_{\mathrm{r}}$ values as is the case with the sheet/oil configuration. To illustrate this effect consider a simple geometry of parallel plate electrodes 
separated by a layer of solid material and a layer of liquid as seen in Fig. 5.

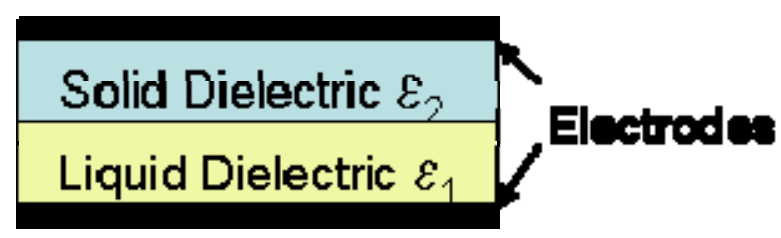

Figure 5: Parallel plates separated by two dielectric layers.

Electrically, this configuration can be represented by two capacitors in series, as shown in Fig. 6.

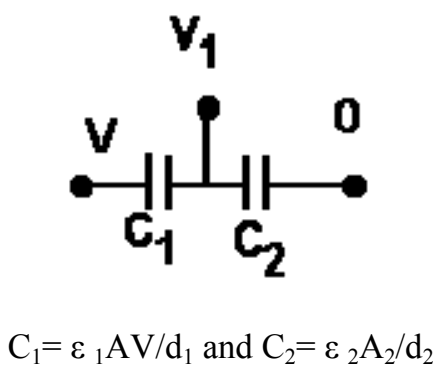

Fig. 6 Capacitor equivalent for parallel plate geometry

The voltage $\mathrm{V}_{1}$ is related to the total voltage by:

$$
\frac{V_{1}}{V}=\frac{C_{1}}{C_{1}+C_{2}}
$$

so that the smaller $\mathrm{C}_{1}$ is with relation to $\mathrm{C}_{2}$, the less voltage $\left(\mathrm{V}_{1}\right)$ appears across $\mathrm{C}_{2}$.

Since the capacitance in this configuration is proportional to $\varepsilon_{\mathrm{r}}$ (see Fig. 6), the smaller $\varepsilon_{1}$ is with respect to $\varepsilon_{2}$, the less voltage appears across the solid dielectric and the more voltage appears across the liquid resulting in a concentration of electric field in the liquid.

In the two sphere sheet/oil configuration, the same principle holds. If the sheet has a much higher $\varepsilon_{\mathrm{r}}$ than the liquid, the electric field (E) in the liquid is increased. In our case where the sheet has $\varepsilon_{2}=10$ or higher, and the fluid is transformer oil with $\varepsilon_{1}=2.5$, this is certainly the case. The peak $\mathrm{E}$ in the oil is much higher than in the slab. When the peak $E$ in the oil exceeds its breakdown strength a discharge forms in the liquid and then initiates breakdown in solid dielectric. This breakdown in the solid dielectric occurs at a substantially lower voltage than is representative of the intrinsic breakdown strength of that material.

A more precise FEA calculation is shown in Fig. 7 that confirms this conclusion. The regions of highest field are in the oil and the triple point where the electrode, the solid insulator and the oil meet. As long as this triple point and disparity in $\varepsilon_{\mathrm{r}}$ exist, the system will break down at substantially lower values than the intrinsic material breakdown strength.

One means of minimizing the effect of the $\varepsilon_{\mathrm{r}}$ disparity is to embed the electrodes into the high $\varepsilon_{\mathrm{r}}$ solid dielectric, at least as far as the region of high field. In the capacitor representation, this is equivalent to making $\mathrm{C}_{1}$ infinite (no oil layer) so all the voltage (and all the field $\mathrm{E}$ ) appears across the solid $\mathrm{C}_{2}$. The configuration now becomes a test that more accurately represents dielectric strength of the solid material.

The final effect is the gap dependent reduction in breakdown field gradient in the case of the buried electrodes that exceeds what can be attributed to the aforementioned geometric field enhancement. This reduction in dielectric strength with insulator volume is normally observed for solid dielectrics [3].
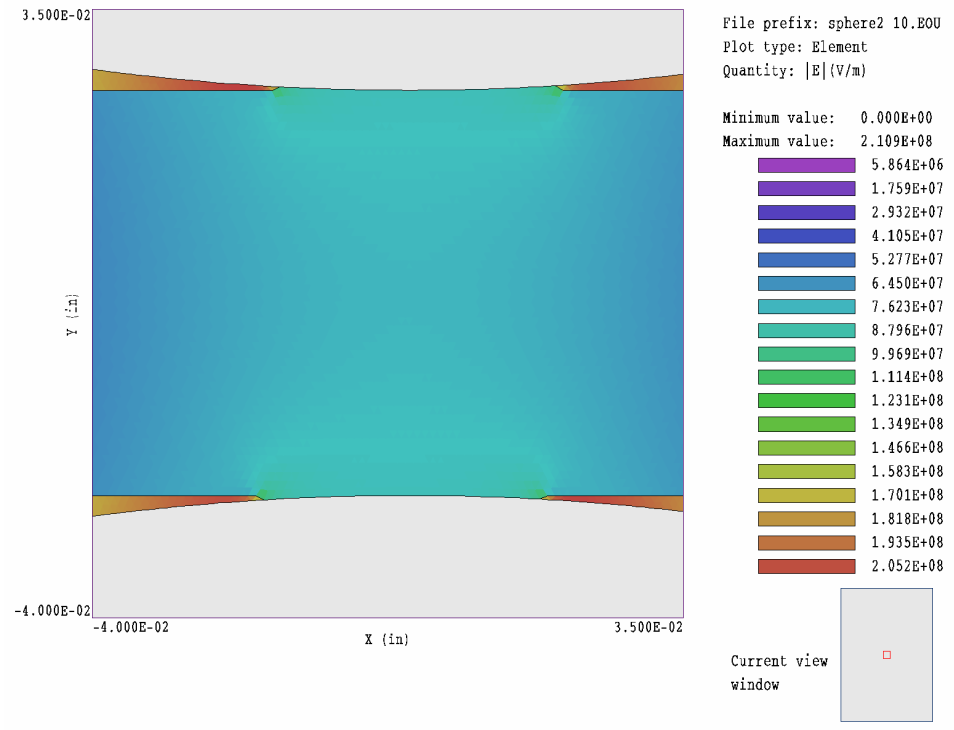

Fig. 7. FEA plot of the field concentration resulting a significant difference in $\varepsilon_{\mathrm{r}}$ between solid dielectric and oil.

It is thought to be the consequence of increased probability of finding a material defect where electrical failure can be initiated. We intend to explore this effect in this particular material system in future work.

\section{CONCLUSION}

We have compared the dielectric behavior of two materials for high voltage insulators. The relative permittivity of 10 for the two materials showed a similar frequency behavior. The dielectric loss, however, was over a factor of 6 times lower for the composite 2 . 
Bulk breakdown measurements were made under pulsed conditions with ball electrodes in sheet/oil and buried electrode configurations as pictured in Fig. 2. The composite 2 exhibited an approximate $30 \%$ improvement over the traditional composite \#1 in the sheet/oil configuration where these materials could be compared.

A further $>2 \mathrm{X}$ improvement was seen when the composite 2 material was cast around the electrodes, effectively removing negative effect of the lower relative permittivity liquid in electrical series with the higher $\varepsilon_{\mathrm{r}}$ solid.

\section{REFERENCES}

[1]. G.J. Caporaso, "Induction LINACS and Pulser Power." Fontiers in Accelerator Technology, p. 594, 1996.

[2]. S.T. Pai and Qi Zhang Introduction to High Power Pulse Technology World Scientific p. 51, 1995

[3]. J.C. Martin, J.C. Martin on Pulsed Power Plenum Press, 1996 p.227

\section{ACKNOWLEDGMENT}

This work was performed under the auspices of the U.S. Department of Energy by University of California, Lawrence Livermore National Laboratory under Contract W-7405-Eng48. 